\title{
PRIMJENA SNSQUAL MODELA U MJERENJU KVALITETE DRUŠTVENIH MREŽA
}

\author{
Suzana Marković
}

Dr. sc., redovita profesorica, Sveučilište u Rijeci, Fakultet za menadžment u turizmu i ugostiteljstvu, Primorska 42, 51410 Opatija, Hrvatska; e-mail: suzanam@fthm.hr

\section{SAŽETAK}

Društvene mreže postale su važan alat za prijenos informacija i povezivanje pojedinaca. lako ne postoji dobna granica za korištenje društvenih mreža, najččšce ih koristi mlađa populacija. Pregled literature pokazuje da postoji niz istraživanja kvalitete usluga u on-line okruženju, ali su rijetka ona koja istražuju kvalitetu društvenih mreža. U ovom je istraživanju, u surhu mjerenja kvalitete društvenih mreža, testirana primjena SNSQUAL modela, kojeg su razvili Phillips et al. (2016). Model obuhvaća varijable koje opisuju jednostavnost korištenja, povjerenje, personalizaciju, pouzdanost i integraciju usluga na društvenim mrežama. Istraživanje je provedeno na uzorku studenata, te je prikupljen 341 ispravno ispunjen anketni upitnik. Prikupljeni podaci su analizirani primjenom metoda deskriptivne statističke analize, faktorske analize i analize pouzdanosti. Rezultati istraživanja ukazuju na visoku razinu percipirane kvalitete društvenih mreža. Ujedno se kvaliteta društvenih mreža u Hrvatskoj percipira kroz sljedeće dimenzije: informacije, jednostavnost korištenja, pouzdanost i sigurnost, integriranost i prilagođavanje.

Ključne riječi: kvaliteta e-usluge, SNSQUAL, društvene mreže, mjerenje, faktorska analiza

\section{UVOD}

Razvoj informacijsko-komunikacijske tehnologije i svakodnevno korištenje interneta utjecali su na promjene u privatnom i poslovnom životu pojedinaca. Te se promjene prije svega ogledaju u načinu komuniciranja i informiranja, pri čemu veliku ulogu imaju društveni mediji. Prema Kaplan i Haenlein (2010), društveni mediji su skup internetskih aplikacija temeljenih na Web 2.0 tehnologiji, koje omogućavaju stvaranje i razmjenu sadržaja koje su kreirali sami korisnici. Društveni mediji obuhvaćaju društvene mreže, blogove, multimedijske platforme, internetske forume, razne virtualne zajednice.

Društvene mreže, kao vrsta društvenih medija, omogućavaju korisnicima kreiranje osobnih profila, stvaranje sadržaja i razmjenu poruka s drugim korisnicima mreže (Boyd i Ellison, 2007). Omogućavaju brzu komunikaciju i interakciju, utječu na informiranost pojedinaca, te posljedično i na donošenje odluka o kupnji. Zbog toga se na društvene mreže više ne gleda isključivo kao na oblik zabave za 
mlađu populaciju, već ih poduzeća sve češće koriste za promociju svojih usluga i proizvoda, te postaju važan marketinški alat na internetu.

Popularnost i rasprostranjenost korištenja društvenih medija i društvenih mreža potvrđuju podaci Global social media research summary (2019), prema kojima je u 2019. godini $45 \%$ svjetske populacije aktivno koristilo društvene medije, dok je prema podacima Statista Report (2019), najpopularnija društvena mreža bila Facebook s više od 2,4 milijarde korisnika. U Hrvatskoj je u 2019. godini društvene mreže koristilo 54 \% osoba. Najpopularnija društvena mreža bila je Facebook s više od 2 milijuna korisnika (Statista Report Croatia, 2019).

Važnost istraživanja kvalitete društvenih mreža ogleda se upravo u ulozi koju društvene mreže imaju u društvenom i ekonomskom smislu, te u pozitivnom utjecaju kvalitete usluga na zadovoljstvo i lojalnost klijenata. lako postoji niz istraživanja kvalitete usluga u on-line okruženju, rijetka su ona koja istražuju kvalitetu društvenih mreža. Stoga ovo istraživanje ima dva osnovna cilja: prvo, ispitati kako korisnici percipiraju kvalitetu društvenih mreža, te drugo, utvrditi faktore koji opisuju kvalitetu društvenih mreža.

Rad je podijeljen u sljedeće cjeline. Nakon uvoda slijedi prikaz prethodnih istraživanja o konceptu kvalitete usluga i mjerenja kvalitete usluga u on-line okruženju. Zatim slijedi opis metodologije istraživanja. $U$ četvrtom su poglavlju prezentirani rezultati provedene deskriptivne i multivarijatne statističke analize. Na kraju su navedeni glavni rezultati istraživanja.

\section{TEORIJSKI OKVIR ISTRAŽIVANJA}

Jedan od najčešće korištenih instrumenata za mjerenje kvalitete usluga u različitim uslužnim djelatnostima je SERVQUAL model kojeg su razvili Parasuraman et al. (1985, 1988). Prema njima, kvaliteta usluge je rezultat usporedbe očekivanja i percepcije dobivene usluge ili proizvoda, te se sastoji od pet glavnih dimenzija (dodirljivost, pouzdanost, odgovornost, stručnost i povjerenje te susretljivost).

S rastom korištenja interneta i njegove uloge u poslovnom i privatnom životu, prepoznata je i potreba istraživanja kvalitete e-usluga. Prema Parasuraman et al. (2005), kvaliteta e-usluge je razina na kojoj web-stranica omogućava uspješnu kupovinu i dostavu proizvoda i usluga.

Pregled literature pokazuje da je nekoliko autora u svojim istraživanjima navodilo osnovne dimenzije (elemente) kvalitete e-usluge. Zeithaml et al. (2002) su predložili jedanaest dimenzija kvalitete e-usluga: pouzdanost, odgovornost, pristup, fleksibilnost, jednostavnost upravljanja, učinkovitost, osiguranje/povjerenje, sigurnost/privatnost, poznavanje cijena, estetika, prilagodba/ personalizacija. Prema Parasuraman et al. (2005), kvalitetu e-usluge čine učinkovitost, dostupnost sustava, ispunjenje, privatnost, odgovornost, korištenje i kontakt. Zhang et al. (2015) su zaključili da na kvalitetu e-usluga utječu praktičnost, točnost informacija, sigurnost i funkcionalnost. Ujedno, Farida et al. (2014) navode da se u istraživanjima o kvaliteti web-stranica kao najčešće dimenzije javljaju kvaliteta informacija, privatnost/sigurnost/osiguranje, pouzdanost/ispunjenje, kvaliteta usluge i kvaliteta sustava. 
lako je SERVQUAL model razvijen za mjerenje kvalitete „tradicionalnih“ usluga, korišten je i u kontekstu mjerenja kvalitete e-usluga (Li et al., 2002; Jiang et al., 2002; Santos, 2003; Collier i Bienstock, 2006; Cristobal et al. 2007). Ipak, činjenica da se e-usluga po svojim karakteristikama razlikuje od "tradicionalne" usluge na čije karakteristike utječu i opipljivi elementi okruženja u kojem se pruža, dovela je do potrebe razvoja modela dizajniranih upravo za mjerenje kvalitete usluga u on-line okruženju.

U tu svrhu razvijeni su SITEQUAL (Yoo i Donthu, 2001), WebQual (Barnes i Vidgen, 2002; (Loiacono et al. 2002), eTailQ (Wolfinbarger i Gilly 2003), E-S-Qual (Parasuraman et al., 2005), hijerarhijski model kvalitete e-usluge (Blut et al. 2015; Blut, 2016), SNSQUAL (Phillips et al., 2016). Navedeni modeli u pravilu mjere kvalitetu e-usluga i kvalitetu web-stranica, dok SNSQUAL model (Phillips et al., 2016) mjeri kvalitetu društvenih mreža, te je korišten i u empirijskom dijelu ovog istraživanja.

SNSQUAL model (Social Networking Site Quality Model) razvijen je u svrhu mjerenja kvalitete društvenih mreža (Phillips et al., 2016). Početni model se temeljio na dimenzijama preuzetim iz SERVQUAL modela (Parasuraman et al. (1988) i WebQual modela (Loiacono et al. 2007), uz dodavanje elemenata koji su karakteristični za kontekst društvenih mreža (Chau i Lai, 2003; Zhang i Prybutok, 2005). Konačni model sastoji se od varijabli koje su grupirane u sljedeće dimenzije: jednostavnost korištenja, povjerenje, personalizacija, pouzdanost i integracija.

\section{METODOLOGIJA ISTRAŽıVANJA}

Osnovna svrha ovog istraživanja bila je mjerenje kvalitete društvenih mreža. Iz toga proizlaze sljedeći ciljevi istraživanja: (a) izmjeriti razinu percipirane kvalitete društvenih mreža i (b) utvrditi glavne dimenzije percipirane kvalitete društvenih mreža.

Upitnik za prikupljanje primarnih podataka u ovom istraživanju sastoji se od dva dijela, te je izrađen na temelju SNSQUAL modela (Phillips et al., 2016). Prvi dio upitnika sadrži 26 varijabli s kojima se mjeri kvaliteta društvenih mreža, a odnose se na jednostavnost korištenja, povjerenje, personalizaciju, pouzdanost $i$ integraciju. Ispitanici su razinu slaganja s navedenim tvrdnjama ocjenjivali na ljestvici s pet ocjena, s krajnjim vrijednostima „u potpunosti se ne slažem“ (1) $\mathrm{i}$ „u potpunosti se slažem“" (5).

Drugi dio upitnika dizajniran je za mjerenje demografskih karakteristika ispitanika, te uključuje sljedeće varijable: spol, razina studija, registrirane društvene mreže, vrijeme provedeno na društvenim mrežama, godine korištenja društvenih mreža, korištena društvena mreža i svrha korištenja društvenih mreža.

Istraživanje je provedeno na uzorku studenata preddiplomskog i diplomskog sveučilišnog studija koji su bili spremni sudjelovati $u$ istraživanju. Uzorak je prigodni, iako se prilikom prikupljanja podataka nastojalo obuhvatiti studente svih godine studija, te tako osigurati uzorak koji po svojim karakteristikama ima svojstva reprezentativnosti. Prikupljanje podataka provedeno je tijekom svibnja 2019. godine. Prikupljeno je 344 upitnika, od čega je 341 upitnik bio ispravno ispunjen, te taj uzorak čini osnovu za analizu prikupljenih podataka. 
Metode deskriptivne statističke analize korištene su za opis demografskih karakteristika ispitanika, te za ocjenu razine kvalitete društvenih mreža. Eksploratorna faktorska analiza primijenjena je za utvrđivanje faktorske strukture kvalitete društvenih mreža. Ujedno je pouzdanost mjerne ljestvice kvalitete društvenih mreža testirana izračunavanjem Cronbach alpha koeficijenata.

\section{REZULTATI ISTRAŽIVANJA}

U ovom dijelu rada prezentirani su rezultati provedene deskriptivne i multivarijatne statističke analize.

\section{1 Profil ispitanika}

Demografski profil ispitanika prikazan je u tablici 1.

Tablica 1. Demografske karakteristike ispitanika $(N=341)$

\begin{tabular}{lclc}
\hline Varijabla & Postotak & Varijabla & Postotak \\
\hline Spol & & Vrijeme provedeno na DM & \\
Muški & 26,4 & Manje od 30 minuta & 4,4 \\
Ženski & 73,6 & 30 minuta- 1 sat & 13,5 \\
& & 1 sat dnevno & 20,8 \\
Razina studija & & 2-3 sata dnevno & 40,5 \\
Preddiplomski & 71,0 & Više od 4 sata dnevno & 20,8 \\
Diplomski & 29,0 & & \\
& & & \\
Registrirane DM & & Godine korištenja DM & \\
1-2 & 42,8 & Manje od 1 godine & 1,2 \\
3-4 & 44,0 & 1-2 godine & 1,2 \\
5-6 & 11,1 & 3-4 godine & 11,7 \\
više od 7 & 2,1 & 5-6 godina & 22,6 \\
& & Više od 6 godina & 63,3 \\
& & & \\
Korištena DM* & & Surha korištenja DM* & \\
Facebook & 76,0 & Komunikacija & 93,5 \\
Twitter & 0,6 & Informiranje & 64,2 \\
Googleplus & 6,7 & Dijeljenje informacija & 47,2 \\
Linkedin & 2,9 & Pregledavanje informacija & 61,3 \\
Myspace & 0,6 & Igranje/zabava & 33,4 \\
Instagram & 32,6 & Učenje & 28,7 \\
Pinterest & 4,4 & Upoznavanje & 27,0 \\
Tumblr & 1,5 & & \\
\hline Napomena: DM - društvena & mreža. ${ }^{*}$ - moguće je zaokružiti više odgovora. &
\end{tabular}

Izvor: rezultati istraživanja 
Iz tablice 1 vidljivo je da u uzorku od 341 ispitanika prevladavaju žene (73,6 \%). Većina ispitanika studira na preddiplomskom stručnom studiju (71\%) i na društvenim mrežama najčešće provede više od 2 sata dnevno (61,3\%). Oko $86 \%$ ispitanika registrirano je na 1 do 4 društvene mreže, te ih oko $63 \%$ koristi društvene mreže više od 6 godina. Najčešće korištene društvene mreže u uzorku su Facebook (76 \%) i Instagram (32,6 \%), dok Twitter, Myspace i Tumblr koristi manje od $3 \%$ ispitanika. Osnovna svrha korištenja društvenih mreža je komunikacija (93,5\%), informiranje $(64,2 \%)$ i pregledavanje informacija (61,3\%). S druge strane, društvene mreže se najmanje koriste u svrhu učenja $(28,7 \%)$ i upoznavanja ( $27 \%)$.

\section{2 Dimenzije percipirane kvalitete društvenih mreža}

Prema rezultatima u tablici 2, prosječne ocjene pojedinih elemenata kvalitete društvenih mreža nalaze se u rasponu od 2,93 do 4,58. Najnižom prosječnom ocjenom ocijenjena je varijabla „vjerujem da su moji podaci sigurni“, što ukazuje da ispitanici imaju podijeljeno mišljene o sigurnosti podataka na društvenim mrežama (niti se slažu, niti se ne slažu s navedenom tvrdnjom). Najvišom prosječnom ocjenom ocijenjena je varijabla „DM je jednostavna za korištenje“. Prema tome, ispitanici u pravilu percipiraju društvene mreže jednostavnima za korištenje, te se u prosjeku u potpunosti slažu s navedenom tvrdnjom. Ukupna prosječna ocjena za percipiranu kvalitetu društvenih mreža iznosi 3,88, te pokazuje visoku percepciju kvalitete društvenih mreža.

Nadalje, cilj provođenja faktorske analize je izlučiti glavne faktore (dimenzije) percipirane kvalitete društvenih mreža. Faktorska analiza provest će se na 26 varijabli tj. elemenata kvalitete društvenih mreža.

Prikladnost za provođenje faktorske analize procijenjena je Kaiser-Mayer-Olkinovom mjerom (KMO) i Bartlettovim testom. Kao što je prikazano u tablici 2, KMO mjera ima visoku vrijednost, a Bartlettov test je značajan na razini 0,01, te se može zaključiti da su podaci prikladni za provođenje faktorske analize i za utvrđivanje faktorske strukture za percipiranu kvalitetu društvenih mreža.

Tablica 2. Rezultati faktorske analize i analize pouzdanosti za pojedine elemente kvalitete društvenih mreža

\begin{tabular}{|c|c|c|c|c|c|}
\hline Varijable & $\begin{array}{c}\text { A.S. } \\
\text { (S. D.) }\end{array}$ & $\begin{array}{c}\text { Faktorska } \\
\text { opterećenja }\end{array}$ & $\begin{array}{c}\text { Svojstvena } \\
\text { vrijednost }\end{array}$ & $\begin{array}{c}\% \\
\text { varijance }\end{array}$ & $\begin{array}{c}\text { Cronbach } \\
\text { alpha }\end{array}$ \\
\hline Faktor 1 & & & 4,816 & 17,052 & 0,924 \\
\hline $\begin{array}{c}\text { DM pruža pouzdane } \\
\text { informacije }\end{array}$ & $\begin{array}{c}3,40 \\
(0,991)\end{array}$ & 0,809 & & & \\
\hline $\begin{array}{c}\text { Sveukupno informacije } \\
\text { koje DM pruža su visoke } \\
\text { kvalitete }\end{array}$ & $\begin{array}{c}3,41 \\
(1,110)\end{array}$ & 0,799 & & & \\
\hline $\begin{array}{c}\text { DM pruža točne } \\
\text { informacije }\end{array}$ & $\begin{array}{c}3,45 \\
(1,021)\end{array}$ & 0,776 & & & \\
\hline
\end{tabular}




\begin{tabular}{|c|c|c|c|c|c|}
\hline Varijable & $\begin{array}{l}\text { A.S. } \\
\text { (S. D.) }\end{array}$ & $\begin{array}{c}\text { Faktorska } \\
\text { opterećenja }\end{array}$ & $\begin{array}{l}\text { Svojstvena } \\
\text { vrijednost }\end{array}$ & $\begin{array}{c}\% \\
\text { varijance }\end{array}$ & $\begin{array}{l}\text { Cronbach } \\
\text { alpha }\end{array}$ \\
\hline $\begin{array}{l}\text { Sveukupno smatram } \\
\text { da DM pruža korisne } \\
\text { informacije }\end{array}$ & $\begin{array}{c}3,70 \\
(0,970)\end{array}$ & 0,753 & & & \\
\hline $\begin{array}{c}\text { Zadovoljan sam } \\
\text { informacijama koje DM } \\
\text { pruža }\end{array}$ & $\begin{array}{c}3,73 \\
(0,889)\end{array}$ & 0,713 & & & \\
\hline $\begin{array}{c}\text { DM pruža relevantne } \\
\text { informacije }\end{array}$ & $\begin{array}{c}3,77 \\
(0,950)\end{array}$ & 0,662 & & & \\
\hline Faktor 2 & & & 3,831 & 13,769 & 0,900 \\
\hline $\begin{array}{l}\text { Sučelje je jednostavno za } \\
\text { korištenje }\end{array}$ & $\begin{array}{c}4,47 \\
(0,725) \\
\end{array}$ & 0,844 & & & \\
\hline $\begin{array}{l}\text { DM mogu jednostavno } \\
\text { koristiti }\end{array}$ & $\begin{array}{c}4,57 \\
(0,706)\end{array}$ & 0,830 & & & \\
\hline $\begin{array}{c}\text { DM je jednostavna za } \\
\text { korištenje }\end{array}$ & $\begin{array}{c}4,58 \\
(0,648) \\
\end{array}$ & 0,825 & & & \\
\hline $\begin{array}{c}\text { Sučelje je jednostavno za } \\
\text { razumijevanje }\end{array}$ & $\begin{array}{c}4,38 \\
(0,808)\end{array}$ & 0,796 & & & \\
\hline $\begin{array}{l}\text { Jednostavno je koristiti } \\
\text { društvenu mrežu }\end{array}$ & $\begin{array}{c}4,38 \\
(0,775)\end{array}$ & 0,662 & & & \\
\hline Faktor 3 & & & 3,810 & 12,699 & 0,897 \\
\hline $\begin{array}{c}\text { Administratori neće } \\
\text { zloupotrijebiti moje } \\
\text { podatke }\end{array}$ & $\begin{array}{c}3,23 \\
(1,003)\end{array}$ & 0,766 & & & \\
\hline $\begin{array}{c}\text { Vjerujem da su moji } \\
\text { podaci sigurni }\end{array}$ & $\begin{array}{c}2,93 \\
(1,198) \\
\end{array}$ & 0,730 & & & \\
\hline DM je pouzdana & $\begin{array}{c}3,39 \\
(0,954)\end{array}$ & 0,675 & & & \\
\hline $\begin{array}{l}\text { Zadovoljan sam } \\
\text { pouzdanošću }\end{array}$ & $\begin{array}{c}3,67 \\
(0,931)\end{array}$ & 0,601 & & & \\
\hline DM se doima pouzdana & $\begin{array}{c}3,59 \\
(0,959) \\
\end{array}$ & 0,591 & & & \\
\hline $\begin{array}{c}\text { DM daje dojam da } \\
\text { ispunjava obećanja i } \\
\text { obaveze }\end{array}$ & $\begin{array}{c}3,54 \\
(0,921)\end{array}$ & 0,566 & & & \\
\hline Faktor 4 & & & 2,965 & 10,885 & 0,815 \\
\hline
\end{tabular}




\begin{tabular}{|c|c|c|c|c|c|}
\hline Varijable & $\begin{array}{l}\text { A.S. } \\
\text { (S. D.) }\end{array}$ & $\begin{array}{c}\text { Faktorska } \\
\text { opterećenja }\end{array}$ & $\begin{array}{l}\text { Svojstvena } \\
\text { vrijednost }\end{array}$ & $\begin{array}{c}\% \\
\text { varijance }\end{array}$ & $\begin{array}{c}\text { Cronbach } \\
\text { alpha }\end{array}$ \\
\hline $\begin{array}{c}\text { DM se integrira sa } \\
\text { ostalim web stranicama }\end{array}$ & $\begin{array}{c}4,11 \\
(0,820) \\
\end{array}$ & 0,742 & & & \\
\hline $\begin{array}{l}\text { Web stranica se ne ruši } \\
\text { često }\end{array}$ & $\begin{array}{c}3,99 \\
(0,991)\end{array}$ & 0,679 & & & \\
\hline Pruža integrirane usluge & $\begin{array}{c}3,76 \\
(0,826) \\
\end{array}$ & 0,676 & & & \\
\hline $\begin{array}{l}\text { Integrira se s ostalim web } \\
\text { stranicama radi pružanja } \\
\text { usluge bez prekida }\end{array}$ & $\begin{array}{c}3,79 \\
(0,883)\end{array}$ & 0,636 & & & \\
\hline $\begin{array}{l}\text { DM nema često } \\
\text { tehničkih problema }\end{array}$ & $\begin{array}{c}3,79 \\
(1,005)\end{array}$ & 0,617 & & & \\
\hline Faktor 5 & & & 2,639 & 8,795 & 0,816 \\
\hline $\begin{array}{c}\text { DM omogućuje } \\
\text { prilagodbu sadržaja } \\
\text { informacija ovisno o } \\
\text { potrebama }\end{array}$ & $\begin{array}{c}3,89 \\
(0,871)\end{array}$ & 0,756 & & & \\
\hline $\begin{array}{l}\text { DM omogućuje } \\
\text { prilagodbu informacija } \\
\text { ovisno o potrebama }\end{array}$ & $\begin{array}{c}3,94 \\
(0,837)\end{array}$ & 0,751 & & & \\
\hline $\begin{array}{c}\text { U mogućnosti sam biti u } \\
\text { interakciji s DM }\end{array}$ & $\begin{array}{c}3,96 \\
(0,827)\end{array}$ & 0,658 & & & \\
\hline $\begin{array}{c}\text { DM mi omogućuje } \\
\text { personalizaciju izgleda }\end{array}$ & $\begin{array}{c}3,70 \\
(0,954)\end{array}$ & 0,455 & & & \\
\hline Ukupno & 3,88 & & 18,061 & 63,200 & 0,951 \\
\hline $\begin{array}{l}\text { Kaiser-Meyer-Olkin } \\
\text { (KMO) }\end{array}$ & \multicolumn{5}{|c|}{0,931} \\
\hline Bartlettov test & \multicolumn{5}{|c|}{$7372,452,(p<0,01)$} \\
\hline
\end{tabular}

Napomena: Primijenjena je metoda glavnih komponenata (principal component analysis). Metoda rotacije: varimax s Kaiser normalizacijom. Vrijednosti faktorskih opterećenja koje ne pripadaju određenom faktoru nisu prikazane. Vrijednosti u zagradi su standardne devijacije. A. S. - aritmetička sredina. S. D. - standardna devijacija.

Izvor: rezultati istraživanja

Kao što pokazuju rezultati u tablici 2, faktorskom analizom izlučeno je pet faktora koji objašnjavaju 63,2 \% ukupne varijance svih izvornih varijabli. Sva faktorska opterećenja su pozitivna i imaju vrijednost veću od 0,4. Većina faktorskih opterećenja veća je od 0,60, što ukazuje na visoku (jaku) korelaciju između izlučenih faktora i njihovih pripadajućih varijabli. Ujedno, izlučeni faktori sadrže od 4 do 6 
varijabli. Prema tome, svi izlučeni faktori zadovoljavaju kriterije koji prema Hair et al. (2010) upućuju na zadovoljavajuću faktorsku strukturu.

$\mathrm{Na}$ temelju opisa varijabli sadržanih u pojedinom faktoru, izlučeni faktori interpretiraju se na sljedeći način. Faktor 1 („informacije“) sadrži šest varijabli koje se odnose na pouzdane, korisne, točne, relevantne i kvalitetne informacije koje pruža društvena mreža. Faktor 2 (,jednostavnost korištenja“) obuhvaća pet varijabli koje upućuju na jednostavno korištenje društvene mreže i njenog sučelja. Faktor 3 („pouzdanost i sigurnost“) sadrži šest varijabli koje ukazuju na sigurnost podataka i pouzdanost društvene mreže. Faktor 4 (,integriranost“) sadrži pet varijabli povezanih s integriranom uslugom na društvenoj mreži i nedostatkom tehničkih problema. Faktor 5 („prilagođavanje“) ima četiri varijable koje se odnose na mogućnost prilagođavanja potrebama korisnika društvene mreže.

Nadalje, tablica 2 sadrži i rezultate analize pouzdanosti. Cronbach alpha koeficijenti za izlučene faktore percipirane kvalitete društvenih mreža imaju vrijednosti od 0,815 do 0,924. Navedene vrijednosti ukazuju na jaku unutarnju dosljednost i stabilnost faktora. Cronbach alpha koeficijent za cjelokupnu ljestvicu percipirane kvalitete društvenih mreža iznosi 0,951, što prema Hair et al. (2010) pokazuje visoku pouzdanost ljestvice.

Prema navedenim rezultatima, „informacije“, „jednostavnost korištenja“, „pouzdanost i sigurnost“, „integriranost“ i „prilagođavanje“ mogu se smatrati pouzdanim ključnim dimenzijama percipirane kvalitete društvenih mreža.

\section{ZAKLJUČAK}

Osnovna svrha ovog istraživanja bila je empirijski istražiti kvalitetu društvenih mreža testiranjem SNSQUAL modela. Istraživanje je provedeno na uzorku studenata, s obzirom na to da spadaju u dio populacije koja u znatnoj mjeri koristi društvene mreže u svakodnevnom komuniciranju.

Rezultati analize profila ispitanika pokazuju da je najčešće korištena društvena mreža Facebook, iako su ispitanici u pravilu registrirani na više društvenih mreža. Ispitanici pokazuju lojalnost prema društvenim mrežama koje koriste, s obzirom na to da ih je većina registrirana na društvenim mrežama duže od 6 godina. Nadalje, društvene mreže se najčešće koriste u svrhu komuniciranja, a najmanje za učenje i upoznavanje.

Analiza percepcije pojedinih elemenata kvalitete društvenih mreža pokazala je da je najvažniji element kvalitete društvenih mreža njihovo jednostavno korištenje. S druge strane, percepcija sigurnosti podataka i pouzdanosti društvenih mreža je osrednja, te ukazuje na blago nepovjerenje prema društvenim mrežama i zaštiti osobnih podataka. Ipak, ukupna prosječna ocjena svih elemenata kvalitete društvenih mreža iznosi 3,88 , te pokazuje visoku razinu percipirane kvalitete društvenih mreža.

Rezultati faktorske analize pokazuju da se kvaliteta društvenih mreža u Hrvatskoj percipira kroz informacije, jednostavnost korištenja, pouzdanost i sigurnost, integriranost i prilagođavanje. Uspoređujući ove rezultate s prethodnim istraživanjima (Zeithaml et al., 2002; Parasuraman et al., 2005; Farida et al., 2014; Zhang et al., 2015), uočava se djelomično podudaranje u broju i 
interpretaciji dimenzija na temelju kojih korisnici ocjenjuju uslugu u on-line okruženju. Prema tome, struktura dimenzija kvalitete e-usluga prilagođava se kontekstu istraživanja.

Prema tome, društvene mreže trebaju pružati pouzdane, korisne, točne, relevantne i kvalitetne informacije. Važnost ove dimenzije ogleda se u činjenici da su društvene mreže upravo nastale zbog brže i lakše razmjene informacija. Osim toga, i rezultati ovog istraživanja pokazuju da je jedna od osnovnih svrha korištenja društvenih mreža upravo informiranje.

Jednostavnost korištenja društvenih mreža odnosi se na lakoću ostvarenja ciljeva koje korisnici imaju prilikom korištenja društvenih mreža, te ukazuje na stupanj jednostavnosti korištenja usluga. Osigurava učinkovito korištenje društvenih mreža, tj. dostupnost sadržaja.

Pouzdanost označava sposobnost pružanja točne i pouzdane usluge, te ispunjavanje obećanja i obveza. Uz to, korisnici društvenih mreža žele biti sigurni da se s njihovim podacima neće postupati neovlašteno, te je sigurnost podataka bitan element kvalitete društvenih mreža.

Integriranost podrazumijeva ponudu usluga različitih ponuđača na jednom mjestu, tj. dostupnost usluga dogovorenih s drugim partnerima s jednog mjesta. Integrirane usluge omogućavaju korisnicima dostupnost personaliziranim uslugama koje se pružaju po nižim cijenama, što povećava vrijednost usluge za klijenta.

Konačno, prilagođavanje označava sposobnost društvenih mreža da prilagode sadržaje potrebama i željama korisnika. Na taj se način individualizira on-line iskustvo pojedinaca, što posljedično pozitivno utječe na učestalost korištenja društvenih mreža.

Prema tome, kvaliteta društvenih mreža je višedimenzionalan konstrukt, te objedinjava niz karakteristika koje se odnose na iskustvo korištenja društvenih mreža.

Preporuke za buduća istraživanja proizlaze iz ograničenja ovog istraživanja. Rezultati se temelje na uzorku studenata koji, iakočinedominantnu grupukorisnika, nisujedini koji koristedruštvenemreže. Uključivanjem u istraživanje drugih grupa korisnika (mlađih i starijih) osigurali bi se sveobuhvatniji rezultati. Ujedno, to bi omogućilo ispitivanje potencijalnih razlika i sličnosti u percepciji kvalitete društvenih mreža između različitih grupa korisnika. Nadalje, u ovom se istraživanju ne ispituje kvaliteta pojedinih društvenih mreža. U budućim se istraživanjima, stoga, može istražiti imaju li različite društvene mreže različitu strukturu dimenzija koje određuju kvalitetu pojedine društvene mreže. Također, bilo bi zanimljivo testirati povezanost između percipirane kvalitete društvenih mreža te zadovoljstva i lojalnosti njihovih korisnika.

\section{LITERATURA}

Barnes, S. J., Vidgen, R. T. (2002) "An integrative approach to the assessment of e-commerce quality", Journal of Electronic Commerce Research, 3(2), pp. 114-127.

Blut, M. (2016) “E-service quality: development of a hierarchical model”, Journal of Retailing, 92(4), pp. 500-517.

Blut, M., Chowdhry, N., Mittal, V., Brock, C. (2015) “E-service quality: a meta-analytic review”, Journal of Retailing, 91(4), pp. 679-700.

Boyd, D. M., Ellison, N. B. (2007) “Social network sites: Definition, history, and scholarship”, Journal of Computer-Mediated Communication, 13(1), pp. 210-230. 


\section{S. Marković: Primjena SNSQUAL modela u mjerenju kvalitete društvenih mreža Zbornik Veleučilišta u Rijeci, Vol. 9 (2021), No. 1, pp. 131-141}

Chau, P. Y., Lai, V. S. (2003) "An empirical investigation of the determinants of user acceptance of internet banking", Journal of Organizational Computing and Electronic Commerce, 13(2), pp. 123-145.

Collier, J. E., Bienstock, C. C. (2006) “Measuring service quality in e-retailing”, Journal of Service Research, 8(3), pp. 260-275.

Cristobal, E., Flavián, C., Guinalíu, M. (200) "Perceived e-service quality (PeSQ): Measurement validation and effects on consumer satisfaction and web site loyalty", Managing Service Quality, 17(3), pp. 317-340. doi:10.1111 /j.1083-6101.2007.00393.

Farida, F., Suyudi, I., Nuryuliani, N., Hermana, B. (2014) "A review of empirical research on website quality measurement model based on consumer's perception", u: Conference Proceedings of International Conference on Internet Studies, August 16-17, 2014, Singapore.

Global media research summary (2019): https://www.smartinsights.com/social-media-marketing/social-mediastrategy/new-global-social-media-research/ (20. 1. 2020.)

Hair, J. F., Black, W. C., Babin, B. J., Anderson, R. E. (2010) Multivariate Data Analysis: A Global Perspective, 7th Edition, Pearson Education Inc., Upper Saddle River, New Yersey.

Jiang, J. J., Klein, Carr, C. L. (2002) "Measuring information system service quality: SERVQUAL from the other side", MIS Quarterly, 26(2), pp. 145-166.

Kaplan, A. M., Haenlein, M. (2010) “Users of the world, unite! The challenges and opportunities of social media”, Business Horizons, 53(1), pp. 59-68. http://dx.doi.org/10.1016/j.bushor.2009.09.003.

Li, Y., Tan, K., Xie, M. (2002) “Measuring web-based service quality", Total Quality Management, 13(5), pp. 685-700.

Loiacono, E. T., Watson, R. T., Goodhue, D. L. (2002) "WebQual: A measure of website quality, Marketing theory and applications", Marketing Educators Conference: Marketing Theory and Applications, 13, pp. $432-437$.

Loiacono, E. T., Watson, R. T., Goodhue, D. L. (2007) "WebQual: An instrument for consumer evaluation of web site", International Journal of Electronic Commerce, 11(3), pp. 51-87.

Parasuraman, A., Zeithaml, V. A., Berry, L. L. (1985) “A Conceptual Model of Service Quality and Its Implications for Future Research", The Journal of Marketing, 49(4), pp. 41-50.

Parasuraman, A., Zeithaml, V. A., Berry, L. L. (1988) "SERVQUAL: A multiple-item scale for measuring consumer perceptions of service quality", Journal of Retailing, 64(1), pp. 12-40.

Parasuraman, A., Zeithaml, V. A., Malhotra, A. (2005) “E-S-QUAL: A multiple-item scale for assessing electronic service quality", Journal of Service Research, 7(3), pp. 213-233. https://doi. org/10.1177/10946 70504 271156.

Phillips, B., Peak, D., Prybutok, V. (2016) "SNSQUAL: A Social Networking Site Quality Model", Quality Management Journal, 23(3), pp. 19-36.

Santos, J. (2003) “E-service quality: A model of virtual service quality dimensions”, Management Service Quality, 13(3), pp. 233-246.

Statista Report (2019): https://www.statista.com/statistics/272014/global-social-networks-ranked-by-number-ofusers/ (20. 1. 2020.)

Statista Report Croatia (2019): https://www.statista.com/statistics/1029717/facebook-users-croatia/; https://www. statista.com/statistics/384406/social-network-penetration-in-croatia/ (20.1. 2020.)

Wolfinbarger, M., Gilly, M. C. (2003) “Etailq: dimensionalizing, measuring and predicting etail quality”, Journal of Retailing, 79(3), pp. 183-198.

Yoo, B., Donthu, N. (2001) “Developing a scale to measure the perceived quality of an Internet shopping site (SITEQUAL)”, Quarterly journal of electronic commerce, 2(1), pp. 31-47.

Zeithaml, V. A., Parasuraman, A., Malhotra, A. (2002) "Service quality delivery through web sites: A critical review of extant knowledge" Journal of the Academy of Marketing Science, 30(4), pp. 362-375. https://doi.org/10.1177/00920 7002236911.

Zhang, M., Huang, L., He, Z., Wang, A. G. (2015) "E-service quality perceptions: an empirical analysis of the Chinese e-retailing industry", Total Quality Management, 26(12), pp. 1357-1372.

Zhang, X., Prybutok, V. R. (2005) "A consumer perspective of e-service quality", IEEE Transactions on Engineering Management, 52(4), pp. 461-477. 


\title{
APPLICATION OF SNSQUAL MODEL IN MEASUREMENT OF SOCIAL NETWORK QUALITY
}

\author{
Suzana Marković
}

PhD, Full Professor, University of Rijeka, Faculty of Tourism and Hospitality Management, Primorska 42, 51410 Opatija, Croatia; e-mail: suzanam@fthm.hr

\begin{abstract}
Social networks have become important tool for disseminating information and connecting people. Although there is no age limit for using social networks, they are most frequently used by younger population. Literature review implies that there is number of service quality studies in on-line environment. However, there is a lack of studies about the social network quality. For the purpose of measuring social network quality, SNSQUAL model designed by Phillips et al. (2016) was tested in present study. The model comprised variables that describe ease of use, trust, personalization, reliability, and integration of services on social networks. The research was conducted among the students. A total of 341 valid questionnaires were gathered. Data was analysed using descriptive statistics, factor analysis and reliability analysis. Study results indicate high level of perceived social networks quality. In addition, social network quality in Croatia is perceived through following dimensions: information, ease of use, reliability and safety, integration, and customization.
\end{abstract}

Key words: e-service quality, SNSQUAL, social networks, measurement, factor analysis 
